\title{
Evaluations on Profiles of the Eddy Diffusion Coefficients through Simulations of Super Typhoons in the Northwestern Pacific
}

\author{
Jimmy Chi Hung Fung ${ }^{1,2}$ and Guangze Gao ${ }^{1}$ \\ ${ }^{1}$ Department of Mathematics, The Hong Kong University of Science and Technology, Clear Water Bay, Kowloon, Hong Kong \\ ${ }^{2}$ Division of Environment, The Hong Kong University of Science and Technology, Clear Water Bay, Kowloon, Hong Kong
}

Correspondence should be addressed to Jimmy Chi Hung Fung; majfung@ust.hk

Received 29 August 2016; Revised 29 October 2016; Accepted 14 November 2016

Academic Editor: Rossella Ferretti

Copyright (C) 2016 J. C. H. Fung and G. Gao. This is an open access article distributed under the Creative Commons Attribution License, which permits unrestricted use, distribution, and reproduction in any medium, provided the original work is properly cited.

\begin{abstract}
The modeling of the eddy diffusion coefficients (also known as eddy diffusivity) in the first-order turbulence closure schemes is important for the typhoon simulations, since the coefficients control the magnitude of the sensible heat flux and the latent heat flux, which are energy sources for the typhoon intensification. Profiles of the eddy diffusion coefficients in the YSU planetary boundary layer (PBL) scheme are evaluated in the advanced research WRF (ARW) system. Three versions of the YSU scheme (original, K025, and K200) are included in this study. The simulation results are compared with the observational data from track, center sealevel pressure (CSLP), and maximum surface wind speed (MWSP). Comparing with the original version, the K200 improves the averaged mean absolute errors (MAE) of track, CSLP, and MWSP by $6.0 \%, 3.7 \%$, and $23.1 \%$, respectively, while the K025 deteriorates the averaged MAEs of track, CSLP, and MWSP by $25.1 \%, 19.0 \%$, and $95.0 \%$, respectively. Our results suggest that the enlarged eddy diffusion coefficients may be more suitable for super typhoon simulations.
\end{abstract}

\section{Introduction}

The PBL is important for the typhoon intensification since the turbulent mixing in the PBL affects the momentum and heat in the typhoons. However, it is still not possible to fully resolve the diffusion processes within the boundary layer due to the limitations of physical models and grid resolution. Therefore, the boundary layer parameterizations are required to model the sub-grid-scale effects. Among various boundary layer schemes, the first-order turbulence closure schemes are widely used in the tropical cyclone studies and the weather research and forecasting (WRF) model. Comparing with higher-order turbulence closure schemes, the firstorder schemes are computationally cheaper. The simplest first-order schemes are based on the local-K approach. However, the eddy transportation in the planetary boundary layer is mainly conducted by large eddies, which should be represented by bulk properties of the $\mathrm{PBL}$, rather than local properties. Therefore, the nonlocal first-order schemes were developed to resolve this problem and keep the simplicity at the same time.

The eddy diffusivity' modeling is fundamental to the firstorder turbulence closure PBL schemes. We briefly go through the history of the eddy diffusivity' developments. In the study of O'brien, the eddy diffusivity for momentum $K(z)$ is parameterized as

$$
K(z)=\kappa u_{*} \frac{z}{1+\phi(z)},
$$

where $\kappa$ is the von Kármán's constant, $u_{*}$ is the friction velocity, and $\phi(z)$ is the stability function [1].

In Brost and Wyngaard, the eddy diffusivity for momentum $K_{m}$ is represented by

$$
K_{m}=\kappa u_{*} h \frac{(z / h)(1-z / h)^{1.5}}{1+4.7(z / L)},
$$

where $h$ is the boundary layer height and $L$ is the MoninObukhov length [2]. 
In Troen and Mahrt, $K_{m}$ is parameterized as

$$
K_{m}=\kappa u_{*} z \phi_{m}^{-1}\left(1-\frac{z}{h}\right)^{p}
$$

where $\kappa=0.4$ and $\phi_{m}$ is the wind profile function at the top of the surface layer [3]. They further assumed that

$$
w_{s} \equiv\left(u_{*}^{3}+7 \epsilon \kappa w_{*}^{3}\right)^{1 / 3}=u_{*} \phi_{m}^{-1}
$$

where $w_{*}$ is the convective velocity scale and $\epsilon=0.1$ is the fraction of the surface layer height and the boundary layer height. The Prandtl number in Troen and Mahrt is modeled as

$$
\operatorname{Pr} \equiv \frac{K_{h}}{K_{m}}=\left(\frac{\phi_{h}}{\phi_{m}} \frac{z}{L}+6.5 \kappa \frac{z}{h}\right)^{-1},
$$

where $K_{h}$ is the eddy diffusivity for temperature and moisture and $K_{m}$ is the eddy diffusivity for momentum [3]. $\phi_{h}$ and $\phi_{m}$ are the profile functions for $\theta, q$ and $u, v$, respectively.

Based on Troen and Mahrt, in Hong and Pan, a boundary layer diffusion package was implemented into the NCEP medium-range forecast model $[3,4]$. The turbulence diffusion equations for a prognostic variable $C$ can be expressed by

$$
\frac{\partial C}{\partial t}=\frac{\partial}{\partial z}\left[K_{c}\left(\frac{\partial C}{\partial z}-\gamma_{c}\right)\right],
$$

where $K_{c}$ is the eddy diffusivity for $C$ and $\gamma_{c}$ is the countergradient term for $C$, which was introduced by Deardorff [5]. $C$ can be $u, v$ (horizontal wind components), $\theta$ (potential temperature), and $q$ (water vapor mixing ratio). Same as Troen and Mahrt, the eddy diffusivity for momentum is formulated as

$$
K_{m}=\kappa w_{s} z\left(1-\frac{z}{h}\right)^{p}
$$

where $p$ is the profile shape exponent taken as 2 and $w_{s}$ is the mixed-layer velocity scale [3]. The counter-gradient terms for $\theta$ and $q$ are given by

$$
\gamma_{c}=7.8 \frac{\overline{w^{\prime} c^{\prime}}}{w_{s}}
$$

where $\overline{w^{\prime} c^{\prime}}$ is the corresponding surface flux for $\theta$ and $q$. The boundary layer height is given by

$$
h=\operatorname{Rib}_{\mathrm{cr}} \frac{\theta_{v a}|U(h)|^{2}}{g\left(\theta_{v}(h)-\theta_{s}\right)},
$$

where $\mathrm{Rib}_{\mathrm{cr}}$ is the critical bulk Richardson number, $U(h)$ is the horizontal wind speed at $h, \theta_{v a}$ is the virtual potential temperature at the lowest model level, $\theta_{v}(h)$ is the virtual potential temperature at $h$, and $\theta_{s}$ is the temperature near surface. In Hong and Pan, the Prandtl number is a constant within the whole mixed boundary layer [4]. It is given by

$$
\operatorname{Pr}=\frac{\phi_{h}}{\phi_{m}}+7.8 \kappa \epsilon .
$$

The nonlocal scheme can improve the capability on representing the large eddy turbulence within a well-mixed boundary layer, and it is still computationally cheap as other first-order turbulence closure schemes.

In Hong et al., a revised vertical diffusion package is developed on the basis of Noh et al. [6,7]. The turbulence diffusion equations for the prognostic variables can be expressed by

$$
\frac{\partial C}{\partial t}=\frac{\partial}{\partial z}\left[K_{c}\left(\frac{\partial C}{\partial z}-\gamma_{c}\right)-\overline{\left(w^{\prime} c^{\prime}\right)_{h}}\left(\frac{z}{h}\right)^{3}\right],
$$

where $\overline{\left(w^{\prime} c^{\prime}\right)_{h}}$ is the flux at the inversion layer. The Prandtl number is parameterized as

$$
\begin{aligned}
& \operatorname{Pr}=1+\left(\operatorname{Pr}_{0}-1\right) \exp \left[-\frac{3(z-\epsilon h)^{2}}{h^{2}}\right], \\
& \operatorname{Pr}_{0}=\frac{\phi_{h}}{\phi_{m}}+6.8 \kappa \epsilon,
\end{aligned}
$$

where $\operatorname{Pr}_{0}$ is the Prandtl number at the top of the surface layer. The profile functions $\phi_{h}$ and $\phi_{m}$ are given for different conditions. For unstable and neutral conditions,

$$
\begin{aligned}
& \phi_{m}=\left(1-16 \frac{0.1 h}{L}\right)^{-1 / 4} \\
& \phi_{h}=\left(1-16 \frac{0.1 h}{L}\right)^{-1 / 2} .
\end{aligned}
$$

For the stable condition,

$$
\phi_{m}=\phi_{h}=1+5 \frac{0.1 h}{L}
$$

Comparing with the model proposed by Troen and Mahrt, the new model has the following main features: (1) incorporation of an explicit entrainment term into the heat fluxes; (2) the heat fluxes above the boundary layer height are also parameterized; (3) a profile of the Prandtl number is used, in contrast to the constant value; and (4) nonlocal mixing of momentum is also included [3].

Gopalakrishnan et al. started to use flight-level observations to modify the eddy diffusivity in the first-order planetary boundary layer schemes [8]. In Zhang and Drennan, they investigated the vertical eddy diffusivity in the surface wind regime between 18 and $30 \mathrm{~m} \mathrm{~s}^{-1}$ over the ocean [9]. They showed that the magnitudes of the eddy diffusion coefficients for momentum and latent heat fluxes are comparable, whereas the magnitude of the eddy diffusion coefficient for sensible heat flux is much smaller. The authors noted that the data were limited to wind speeds less than $30 \mathrm{~m} \mathrm{~s}^{-1}$. However, it is quite common to have wind speed higher than $30 \mathrm{~m} \mathrm{~s}^{-1}$ in the super typhoons.

In Gopalakrishnan et al., they studied the impacts of modifying $K_{m}$ and $K_{h}$ to be $25 \%$ or $50 \%$ of the coefficients' original values [8]. To the best of their knowledge, this is the first time that flight-level observations are used as the basis to provide an improvement to the existing boundary layer parameterization schemes. They found that reductions 
of $K_{m}$ and $K_{h}$ to $25 \%$ of their original values (for later references, this version is named as GFS-K025 in this article) produced eddy diffusion coefficients which were consistent with observations. It was also found that the GFS-K025 induced stronger hurricane intensity in the idealized frameworks, compared with the original GFS scheme and the GFSK050. Since it is likely to underestimate the typhoon intensity in numerical models, it is possible that the GFS-K025 can provide better real-time predictions. In Gopalakrishnan et al., the boundary layer scheme used is the Global Forecast System (GFS) scheme [8]. The GFS scheme is a prior version of the YSU scheme, which is based on Hong and Pan [4]. The major difference between these two schemes is that the fluxes in the GFS scheme do not contain an entrainment component.

The eddy diffusivity $K_{m}$ in the YSU scheme and the $K_{m}$ in the GFS scheme have the same formulation:

$$
K_{m}=\kappa w_{s} z\left(1-\frac{z}{h}\right)^{2}
$$

However, the mixed-layer velocity scales $\left(w_{s}\right)$ are modeled differently:

$$
\begin{aligned}
& w_{s}=u_{*} \phi_{m}^{-1}, \quad(\text { in GFS }) ; \\
& w_{s}=\left(u_{*}^{3}+\phi_{m} \kappa w_{* b}^{3} \frac{z}{h}\right)^{1 / 3}, \quad \text { (in YSU). }
\end{aligned}
$$

In Gopalakrishnan et al., they pointed out that a reduction of diffusion would lead to a reduction in the dissipation of the angular momentum in the boundary layer, which would further lead to stronger spin-up and enhanced moisture convergence [8]. The enhanced latent heat flux provides better thermo conditions for tropical cyclones to develop and intensify. However, we also noticed that while the reduction of $K_{m}$ could reduce the sink of momentum and angular momentum, the reduction of $K_{h}$ would also reduce the sources of heat and moisture and weaken the tropical cyclones. It might still be difficult to determine whether the eddy diffusivity coefficients should be enlarged or decreased in the PBL schemes. To make an attempt at addressing this issue, we conduct simulations for the super typhoons in 2014 to evaluate 3 versions of the YSU scheme (original YSU, K025, and K200) in this article.

The YSU scheme is used because it is a state-of-the-art first-order turbulence closure scheme. In the K025 and the K200, the eddy diffusion coefficients are modified to be $25 \%$ and $200 \%$ of their original values, respectively. The rest of this article is organized as follows: in Section 2, methods and numerical simulations are introduced; in Section 3, simulation results are analyzed; and in Section 4, conclusions are provided.

\section{Methods and Numerical Simulations}

In this section, we introduce the designs of the K025 and the K200, the simulated super typhoon cases, the WRF configurations, and the evaluation metrics.

2.1. K-Profiles: Original, K025, and K200. The eddy diffusivity for momentum $\left(K_{m}\right)$ is parameterized in (15). The eddy diffusivity for heat and moisture $\left(K_{h}\right)$ is calculated by $K_{m}$ and
TABLE 1: Simulation periods and durations for super typhoon cases in 2014.

\begin{tabular}{lccc}
\hline Name & Start time (UTC) & End time (UTC) & Duration (h) \\
\hline Neoguri & 06:00, 4 Jul, 2014 & 06:00, 8 Jul, 2014 & 96 \\
Rammasun & 00:00, 14 Jul, 2014 & 00:00, 18 Jul, 2014 & 96 \\
Genevieve & 12:00, 9 Aug, 2014 & 12:00, 11 Aug, 2014 & 48 \\
Phanfone & 00:00, 1 Oct, 2014 & 00:00, 5 Oct, 2014 & 96 \\
Vongfong & 12:00, 5 Oct, 2014 & 12:00, 9 Oct, 2014 & 96 \\
Nuri & 00:00, 1 Nov, 2014 & 00:00, 5 Nov, 2014 & 96 \\
Hagupit & 06:00, 2 Dec, 2014 & 06:00, 6 Dec, 2014 & 96 \\
\hline
\end{tabular}

the Prandtl number (Pr). We introduce a new parameter $\alpha$ to control the magnitudes of $K_{m}$ and $K_{h}$ :

$$
K_{m}=\alpha \kappa w_{s} z\left(1-\frac{z}{h}\right)^{2} .
$$

For the original YSU scheme, $\alpha=1$; for the K025, $\alpha=0.25$; and for the K200, $\alpha=2$. In the K025 and the K200, the eddy diffusion coefficients are modified to be $25 \%$ and $200 \%$ of their original values, respectively.

2.2. Super Typhoon Cases. From 2009, the Hong Kong Observatory (HKO) divides the tropical cyclones into 6 intensity levels: (1) tropical depression: 22-33 knots; (2) tropical storm: 34-47 knots; (3) severe tropical storm: 4863 knots; (4) typhoon: 64-81 knots; (5) severe typhoon: 8299 knots; and (6) super typhoon: $\geq 100$ knots. In this paper, the super typhoon cases in the northwestern Pacific in 2014 are simulated, which are Neoguri, Rammasun, Genevieve, Phanfone, Vongfong, Nuri, and Hagupit. The simulation periods and durations are shown in Table 1.

2.3. WRF Configurations. Numerical simulations are conducted by WRF-ARW v3.5.1. The parent domain (D01) has a horizontal resolution of $27 \mathrm{~km}$, with $199 \times 172$ grids; the middle nest domain (D02) has a resolution of $9 \mathrm{~km}$, with $301 \times 223$ grids; and the inner domain (D03) has a resolution of $3 \mathrm{~km}$, with $469 \times 370$ grids. For each case, the vortex of the tropical cyclone at the initial time is located at the right-bottom corner of D03, which is helpful for the inner domain to cover the tracks as much as possible, since most tropical cyclones in the northwestern Pacific move toward the northwest. The domains are illustrated in Figure 1.

There are 39 vertical layers in all the three domains. The map projection method used for the simulations is the Lambert projection. The time steps are $120 \mathrm{~s}, 40 \mathrm{~s}$, and $40 / 3 \mathrm{~s}$ for D01, D02, and D03, respectively. The current settings for the time steps can satisfy the stability constraints and control the computational cost at the same time. The pressure at the top of the computational domains is set as $50 \mathrm{hPa}$. Two-way nesting has been used for all the simulations. Time varying (6-hourly) sea surface temperature has been used.

The YSU planetary boundary layer scheme is used. The long wave and short wave radiation schemes are the RRTMG schemes. The Grell-Freitas cumulus scheme is applied in D01 and D02. The microphysics scheme is the WRF Singlemoment 6-class (WSM6) scheme. The surface layer scheme 


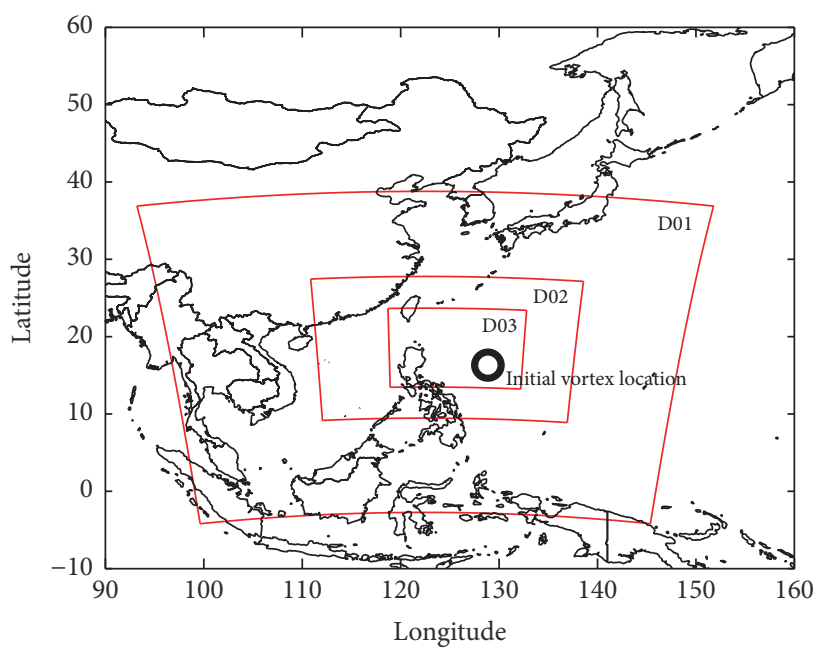

(a)

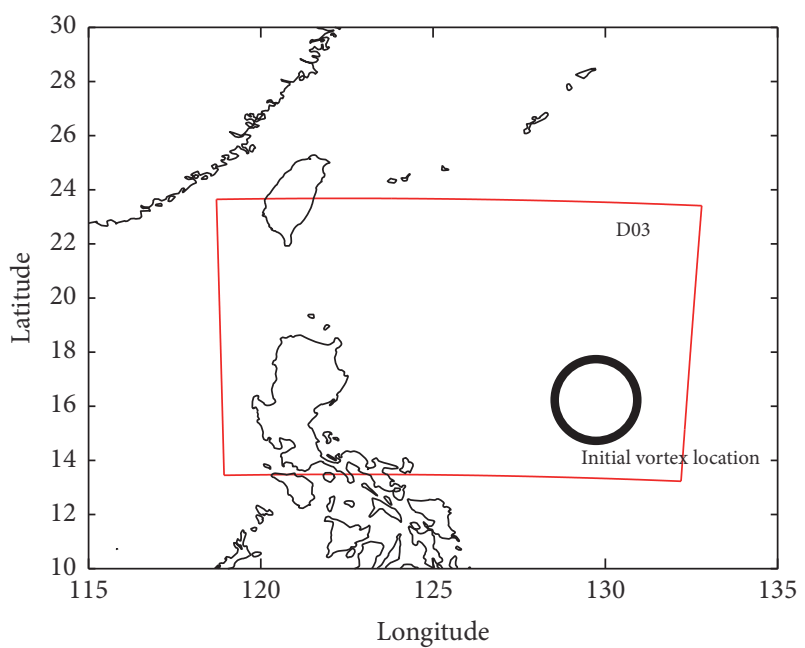

(b)

FIGURE 1: WRF domains: (a) all the domains; (b) D03.

is the MM5 similarity scheme. The land surface model is the Unified Noah Land Surface Model. The initial conditions and the boundary conditions are generated by the FNL (NCEP Final Analyses) data.

2.4. Evaluation Metrics. The simulation results are compared with the observational data from the HKO. The variables to be compared are track, CSLP, and MWSP. The observational data is 6-hourly. Therefore, the simulated data are compared with observations at $t=0,6,12,18,24, \ldots$, h. Consider time series of the observational data $O_{i}$ and the simulated data $S_{i}$, $1 \leq i \leq N$, where $N$ is the number of time points compared; that is, $N=$ (length of simulation) $/ 6+1$. The definition of absolute error (AE) in this article for the $i$ th time point is $\mid S_{i}-$ $O_{i} \mid$, which is slightly different from the traditional definition $\left(S_{i}-O_{i}\right)$. The mean absolute error (MAE) is defined as

$$
\mathrm{MAE}=\frac{1}{N} \sum_{i=1}^{N}\left|S_{i}-O_{i}\right|
$$

The MAE is affected by all the time points during the simulation period equally, which can be used as a variable to evaluate a simulation's overall performance. The improvements made by a new K-profile are evaluated by

improvement of $\mathrm{AE}=\frac{\mathrm{AE}^{\text {original }}-\mathrm{AE}^{\text {new }}}{\mathrm{AE}^{\text {original }}} \times 100 \%$,

improvement of MAE

$$
=\frac{\mathrm{MAE}^{\text {original }}-\mathrm{MAE}^{\text {new }}}{\mathrm{MAE}^{\text {original }}} \times 100 \% \text {, }
$$

where "original" represents the original YSU scheme and "new" represents a new version of YSU scheme with a modified K-profile. The AEs are averaged for all the cases at $t=24,48,72$ and $96 \mathrm{~h}$, which are named as the averaged $\mathrm{AE}$ at $t$. The averaged MAE is defined as the weighted-averaged MAE for all the cases similarly, with the weight equal to the
TABLE 2: Case 1-Neoguri: AE and MAE of track, CSLP, and MWSP.

\begin{tabular}{lccc}
\hline Time $(\mathrm{h})$ & $\begin{array}{c}\mathrm{AE} \text { of track }(\mathrm{km}) \\
\mathrm{K}((1 / 4) \mathrm{K}) \mathbf{2 K}\end{array}$ & $\mathrm{KE}$ of $\operatorname{CSLP}(\mathrm{hPa})$ & $\begin{array}{c}\mathrm{AE} \text { of MWSP } \\
\left(\mathrm{m} \mathrm{s}^{-1}\right)\end{array}$ \\
\hline 24 & $94.8(131.9) \mathbf{9 4 . 8}$ & $5.6(19.1) \mathbf{2 . 0}$ & $\mathrm{K}((1 / 4) \mathrm{K}) \mathbf{2 K}$ \\
48 & $148.2(210.7) \mathbf{9 8 . 6}$ & $22.3(7.5) \mathbf{2 2 . 3}$ & $0.1(19.4) \mathbf{1 . 4}$ \\
72 & $181.2(263.8) \mathbf{2 2 8 . 3}$ & $12.9(6.0) \mathbf{1 0 . 4}$ & $3.9(19.3) \mathbf{1 . 2}$ \\
96 & $242.7(310.5) \mathbf{3 0 3 . 2}$ & $6.5(2.8) \mathbf{3 . 6}$ & $9.4(15.9) \mathbf{2 . 2}$ \\
6-hourly & $140.5(186.6) \mathbf{1 4 4 . 2}$ & $8.4(9.2) \mathbf{7 . 9}$ & $4.5(17.3) \mathbf{2 . 4}$ \\
MAE & & & \\
\hline
\end{tabular}

number of compared time points for each case. In the figures and tables, the units for track, CSLP, and MWSP are $\mathrm{km}, \mathrm{hPa}$, and $\mathrm{m} \mathrm{s}^{-1}$, respectively.

\section{Results}

3.1. Case-Specific Analysis. To evaluate the three versions of YSU, we compare the simulated track, CSLP, and MWSP with their corresponding observational data. The computation of $\mathrm{AE}$ and MAE follows the definitions in Section 2.4. The cases are listed in chronological order.

3.1.1. Case 1: Neoguri. In Figures 2(a), 2(b), and 2(c), the tracks simulated by the original YSU, the K025, and the K200 are similar. In Figures 2(d) and 2(e), it can be observed that the CSLP simulated with the K200 and the original YSU are close to each other. The MWSP simulated with the K200 agrees well with the observational MWSP. It is observed that the MWSP becomes stronger as the eddy diffusion coefficients become larger. As illustrated in Table 2, the MAE of MWSP for the K200 is $2.4 \mathrm{~m} \mathrm{~s}^{-1}$, which is much smaller compared with the MAE of MWSP simulated with the K025 $\left(17.3 \mathrm{~m} \mathrm{~s}^{-1}\right)$.

3.1.2. Case 2: Rammasun. In Figures 3(a), 3(b), and 3(c), it is observed that the track simulated by the K200 agrees well 


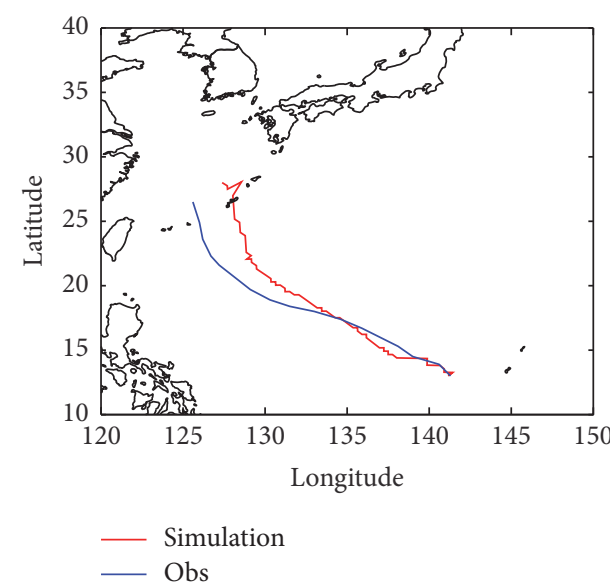

(a)

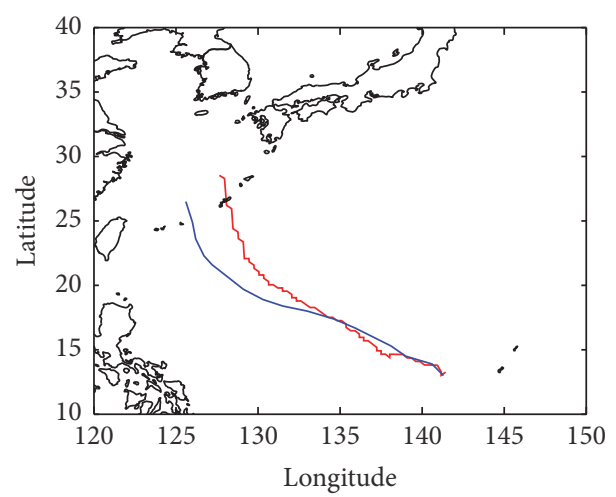

_ Simulation
Obs

(c)

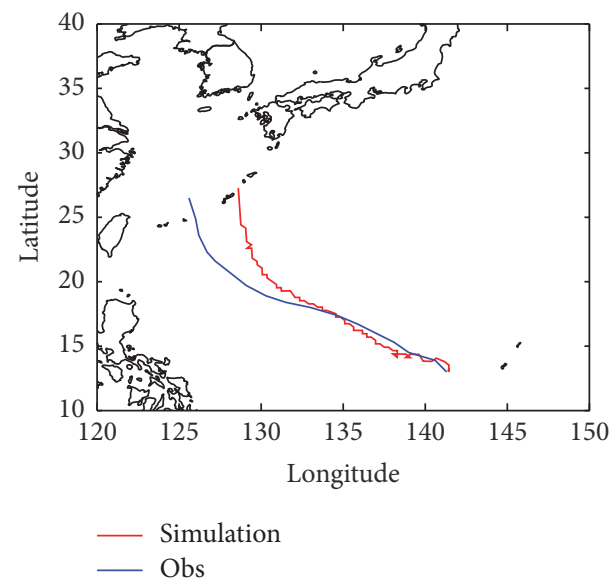

(b)

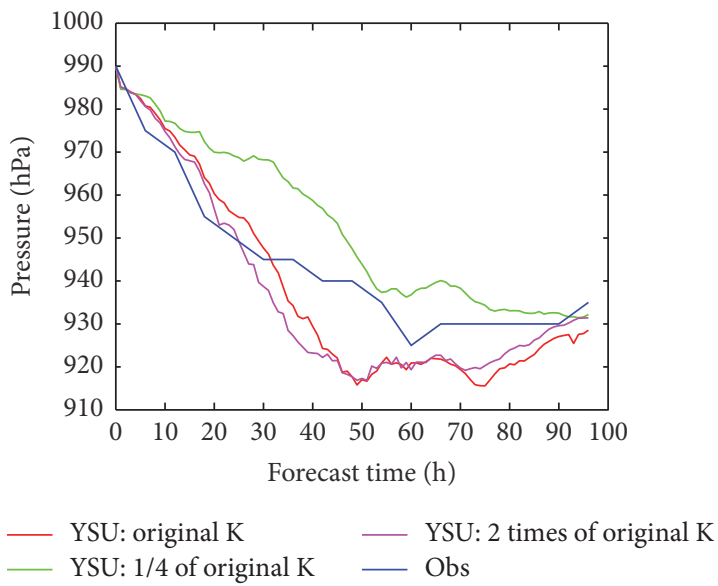

(d)

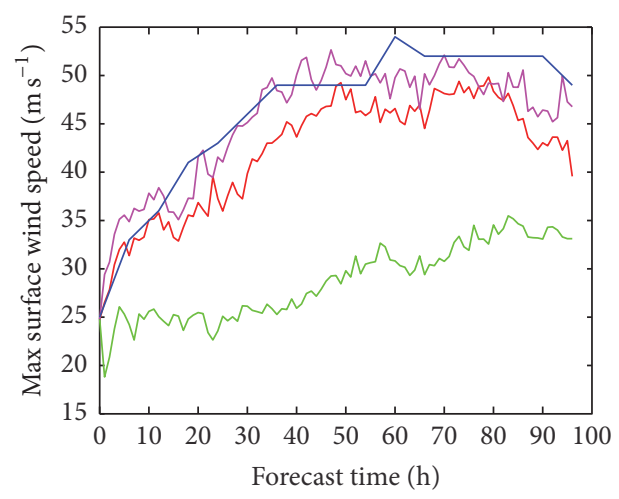

$\begin{array}{ll}\text { YSU: original } \mathrm{K} & - \text { YSU: } 2 \text { times of original } \mathrm{K} \\ \text { YSU: } 1 / 4 \text { of original } \mathrm{K} & \text { Obs }\end{array}$

(e)

FIGURE 2: Case 1-Neoguri: (a) track simulated by the original YSU; (b) track simulated by the K025; (c) track simulated by the K200; (d) comparisons of center sea-level pressure; and (e) comparisons of maximum surface wind speed.

with the observational track and is better than the tracks simulated by the original YSU and the K025 in the middle of the simulation period. As shown in Table 3 , at $t=48 \mathrm{~h}$, the $\mathrm{AE}$ of track simulated by the $\mathrm{K} 200$ is $31.7 \mathrm{~km}$, while the AE of track with the K025 is $134.5 \mathrm{~km}$. In Figures 3(d) and 3(e), it is observed that the intensity variables (CSLP and MWSP) simulated by the original YSU and the K200 are relatively closer to each other, compared with the variables simulated by 

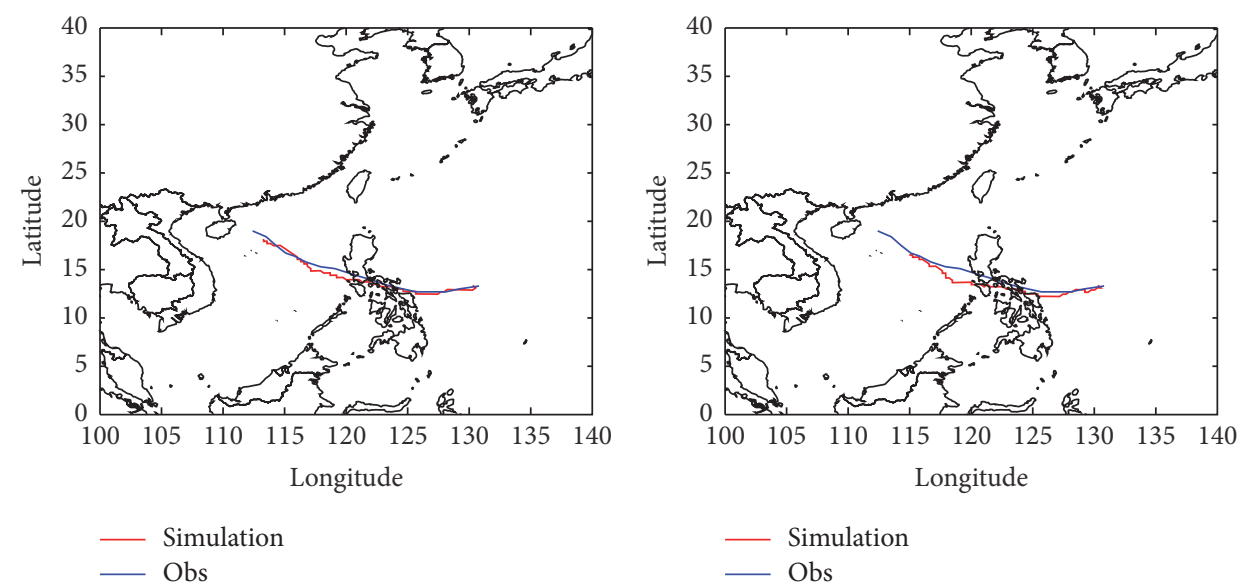

(a)

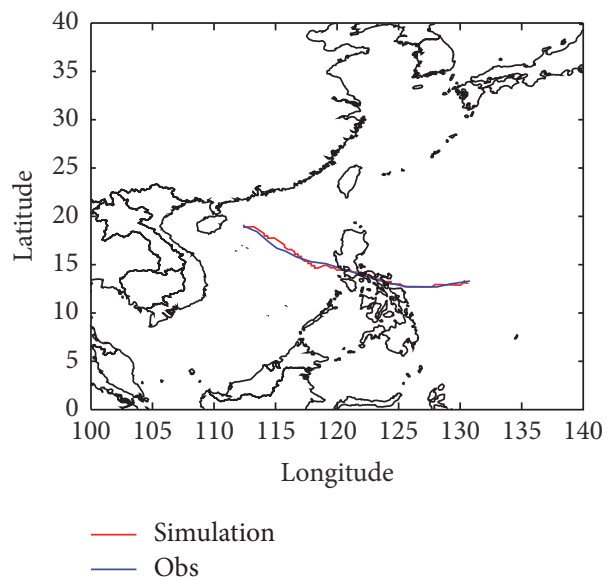

(c)

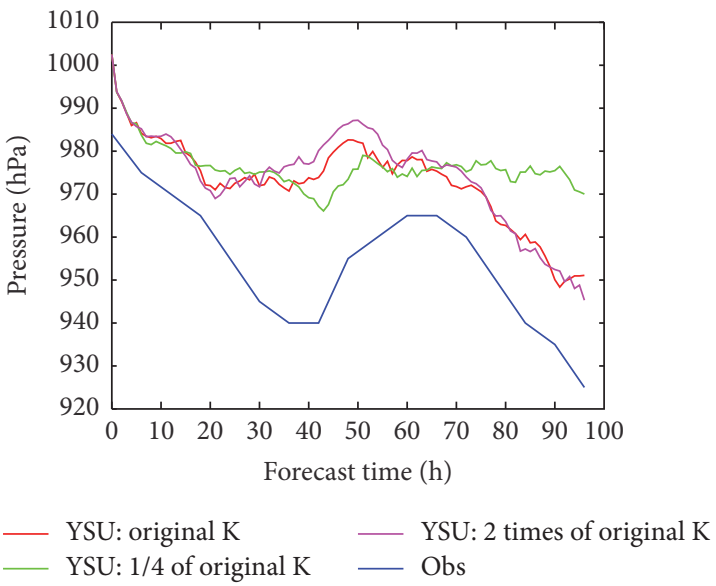

(d)

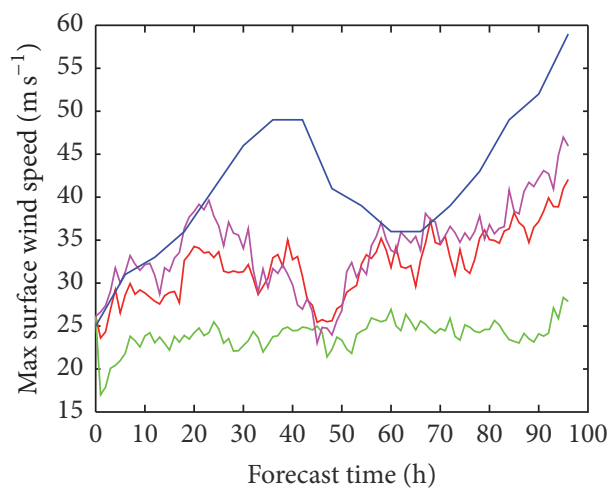

$\begin{array}{ll}\text { YSU: original K } & \text { YSU: } 2 \text { times of original } \mathrm{K} \\ \text { YSU: } 1 / 4 \text { of original K } & \text { Obs }\end{array}$

(e)

FIgURE 3: Case 2-Rammasun: (a) track simulated by the original YSU; (b) track simulated by the K025; (c) track simulated by the K200; (d) comparisons of center sea-level pressure; and (e) comparisons of maximum surface wind speed.

the K025. The MAEs of CSLP simulated by the 3 versions are close to each other. However, the MAE of MWSP simulated with the K025 is much larger than the other 2 versions (Table 3), which is $17.0 \mathrm{~m} \mathrm{~s}^{-1}$. As shown in Figure 3(e), the version of K025 cannot simulate the intensification correctly.
3.1.3. Case 3: Genevieve. In Figures 4(a), 4(b), and 4(c), the track simulated by the $\mathrm{K} 025$ is closer to the observational track and is better than the tracks simulated by the K200 and the original YSU. In Figures 4(d) and 4(e), the CSLP simulated by the $\mathrm{K} 025$ is the best among all the 3 versions, and the 
TABLE 3: Case 2-Rammasun: AE and MAE of track, CSLP, and MWSP.

\begin{tabular}{lccc}
\hline Time $(\mathrm{h})$ & AE of track $(\mathrm{km})$ & $\mathrm{AE}$ of CSLP $(\mathrm{hPa})$ & $\begin{array}{c}\text { AE of MWSP } \\
\left(\mathrm{m} \mathrm{s}^{-1}\right)\end{array}$ \\
& $\mathrm{K}((1 / 4) \mathrm{K}) \mathbf{2 K}$ & $\mathrm{K}((1 / 4) \mathrm{K}) \mathbf{2 K}$ & $\mathrm{K}((1 / 4) \mathrm{K}) \mathbf{2 K}$ \\
\hline 24 & $32.2(51.8) \mathbf{6 7 . 6}$ & $16.3(19.6) \mathbf{1 8 . 6}$ & $8.0(15.5) \mathbf{3 . 2}$ \\
48 & $57.8(134.5) \mathbf{3 1 . 7}$ & $27.6(18.5) \mathbf{3 1 . 4}$ & $15.4(18.7) \mathbf{1 7 . 0}$ \\
72 & $123.6(320.4) \mathbf{8 0 . 2}$ & $11.7(15.2) \mathbf{1 4 . 0}$ & $6.0(13.1) \mathbf{2 . 4}$ \\
96 & $130.7(388.4) \mathbf{1 4 . 3}$ & $26.1(45.0) \mathbf{2 0 . 3}$ & $16.9(31.1) \mathbf{1 3 . 0}$ \\
6-hourly & $74.9(176.2) \mathbf{4 3 . 8}$ & $18.5(22.2) \mathbf{1 9 . 8}$ & $9.2(17.0) 7.4$ \\
MAE & & &
\end{tabular}

TABle 4: Case 3-Genevieve: AE and MAE of track, CSLP, and MWSP.

\begin{tabular}{lccc}
\hline Time $(\mathrm{h})$ & $\begin{array}{c}\mathrm{AE} \text { of track }(\mathrm{km}) \\
\mathrm{K}((1 / 4) \mathrm{K}) \mathbf{2 K}\end{array}$ & $\mathrm{K}((1 / 4) \mathrm{K}) \mathbf{2 K}$ & $\mathrm{K}((1 / 4) \mathrm{K}) \mathbf{2 K}$ \\
\hline 24 & $39.8(80.5) \mathbf{4 0 . 5}$ & $14.4(10.7) \mathbf{1 4 . 3}$ & $8.5(12.4) 5.8$ \\
48 & $136.9(74.1) \mathbf{2 0 4 . 1}$ & $2.1(2.7) 4.9$ & $0.7(2.4) \mathbf{0 . 7}$ \\
6-hourly & $71.8(67.6) \mathbf{1 0 0 . 3}$ & $14.9(12.4) \mathbf{1 6 . 2}$ & $5.6(8.8) \mathbf{4 . 2}$ \\
MAE & & & $\begin{array}{c}\text { AE of MWSP } \\
\left(\mathrm{m} \mathrm{s}^{-1}\right)\end{array}$ \\
\hline
\end{tabular}

TABLE 5: Case 4-Phanfone: AE and MAE of track, CSLP, and MWSP.

\begin{tabular}{lccc}
\hline Time $(\mathrm{h})$ & AE of track $(\mathrm{km})$ & $\mathrm{AE}$ of CSLP $(\mathrm{hPa})$ & $\begin{array}{c}\text { AE of MWSP } \\
\left(\mathrm{m} \mathrm{s}^{-1}\right)\end{array}$ \\
& $\mathrm{K}((1 / 4) \mathrm{K}) \mathbf{2 K}$ & $\mathrm{K}((1 / 4) \mathrm{K}) \mathbf{2 K}$ & $\mathrm{K}((1 / 4) \mathrm{K}) \mathbf{2 K}$ \\
\hline 24 & $84.5(69.2) \mathbf{6 6 . 4}$ & $16.7(25.2) \mathbf{4 . 6}$ & $14.1(23.7) \mathbf{7 . 7}$ \\
48 & $112.8(90.0) \mathbf{8 4 . 8}$ & $16.0(9.6) \mathbf{1 7 . 7}$ & $4.2(20.4) \mathbf{0 . 5}$ \\
72 & $235.1(109.9) \mathbf{1 7 2 . 5}$ & $13.1(11.1) \mathbf{9 . 7}$ & $3.5(19.0) \mathbf{0 . 2}$ \\
96 & $572.5(288.3) \mathbf{4 3 3 . 4}$ & $13.0(14.7) \mathbf{1 3 . 2}$ & $2.5(12.7) \mathbf{6 . 8}$ \\
6-hourly & $174.0(106.8) \mathbf{1 3 3 . 9}$ & $12.2(10.3) \mathbf{1 0 . 8}$ & $4.9(16.9) \mathbf{2 . 9}$ \\
MAE & & &
\end{tabular}

MWSP simulated by the K200 is the best. As shown in Table 4, the MAE of MWSP simulated by the K200 is $4.2 \mathrm{~m} \mathrm{~s}^{-1}$, which is lower than the MAE of MWSP simulated by the K025 $\left(8.8 \mathrm{~m} \mathrm{~s}^{-1}\right)$.

3.1.4. Case 4: Phanfone. In Figure 5 and Table 5, it is observed that the K025 performs better than the K200 in terms of track. The K025 can improve the MAE of track by $38.6 \%$ compared with the original YSU, whereas the K200 can improve the MAE of track by $23.0 \%$. In terms of CSLP, the K025 performs slightly better than the K200 (Table 5). The K025 can improve the MAE of CSLP by $1.9 \mathrm{hPa}$ compared with the original YSU, while the K200 can improve the MAE of CSLP by $1.4 \mathrm{hPa}$. In terms of MWSP, the K200 is much better than the K025. The MAE of MWSP simulated by the K025 is $16.9 \mathrm{~m} \mathrm{~s}^{-1}$; the MAE of MWSP simulated by the K200 is $2.9 \mathrm{~m} \mathrm{~s}^{-1}$; and the MAE of MWSP simulated by the original YSU is $4.9 \mathrm{~m} \mathrm{~s}^{-1}$ (Table 5).

3.1.5. Case 5: Vongfong. In Table 6, the MAE of track simulated by the K200 is $121.0 \mathrm{~km}$, which is lower than the MAE of track simulated by the $\mathrm{K} 025(222.2 \mathrm{~km})$ and the original YSU
TABLE 6: Case 5-Vongfong: AE and MAE of track, CSLP, and MWSP.

\begin{tabular}{lccc}
\hline Time $(\mathrm{h})$ & AE of track $(\mathrm{km})$ & AE of CSLP $(\mathrm{hPa})$ & $\begin{array}{c}\text { AE of MWSP } \\
\left(\mathrm{m} \mathrm{s}^{-1}\right)\end{array}$ \\
\hline 24 & $\mathrm{~K}((1 / 4) \mathrm{K}) \mathbf{2 K}$ & $\mathrm{K}((1 / 4) \mathrm{K}) \mathbf{2 K}$ & $\mathrm{K}((1 / 4) \mathrm{K}) \mathbf{2 K}$ \\
\hline 8 & $143.9(143.9) \mathbf{1 2 5 . 7}$ & $1.9(4.2) \mathbf{3 . 7}$ & $6.0(12.9) \mathbf{3 . 2}$ \\
72 & $149.2(213.6) \mathbf{1 2 3 . 7}$ & $5.4(11.3) \mathbf{9 . 2}$ & $15.0(24.5) \mathbf{9 . 9}$ \\
96 & $183.1(273.3) \mathbf{1 3 5 . 8}$ & $20.7(19.5) \mathbf{2 2 . 2}$ & $22.8(31.2) \mathbf{1 9 . 9}$ \\
6-hourly & $288.0(482.1) \mathbf{2 4 1 . 7}$ & $9.9(14.3) \mathbf{6 . 7}$ & $16.9(27.1) \mathbf{7 . 4}$ \\
MAE & $151.9(222.2) \mathbf{1 2 1 . 0}$ & $11.1(13.4) \mathbf{1 1 . 3}$ & $13.3(21.3) \mathbf{1 0 . 5}$ \\
\hline
\end{tabular}

TABLE 7: Case 6-Nuri: AE and MAE of track, CSLP, and MWSP.

\begin{tabular}{lccc}
\hline Time $(\mathrm{h})$ & $\begin{array}{c}\mathrm{AE} \text { of track }(\mathrm{km}) \\
\mathrm{K}((1 / 4) \mathrm{K}) \mathbf{2 K}\end{array}$ & $\mathrm{KE}$ of $((1 / 4) \mathrm{K}) \mathbf{2 K}$ & $\mathrm{K}((1 / 4) \mathrm{K}) \mathbf{2 K}$ \\
\hline 24 & $90.4(111.2) \mathbf{5 1 . 0}$ & $4.2(14.0) \mathbf{1 . 5}$ & $8.1(18.6) \mathbf{3 . 0}$ \\
48 & $78.2(103.5) \mathbf{7 8 . 2}$ & $31.2(45.4) \mathbf{2 9 . 1}$ & $29.1(39.1) \mathbf{2 4 . 3}$ \\
72 & $107.5(115.3) \mathbf{1 0 7 . 5}$ & $14.9(20.9) \mathbf{1 5 . 2}$ & $14.1(25.5) \mathbf{1 0 . 2}$ \\
96 & $99.2(148.5) \mathbf{1 6 5 . 3}$ & $15.1(33.6) \mathbf{1 4 . 0}$ & $4.7(15.9) \mathbf{6 . 1}$ \\
6-hourly & $84.1(98.8) \mathbf{8 3 . 9}$ & $14.1(24.2) \mathbf{1 4 . 2}$ & $13.2(22.5) \mathbf{1 1 . 2}$ \\
MAE & & &
\end{tabular}

TABLE 8: Case 7-Hagupit: AE and MAE of track, CSLP, and MWSP.

\begin{tabular}{lccc}
\hline Time $(\mathrm{h})$ & AE of track $(\mathrm{km})$ & AE of CSLP $(\mathrm{hPa})$ & $\begin{array}{c}\text { AE of MWSP } \\
\left(\mathrm{m} \mathrm{s}^{-1}\right)\end{array}$ \\
& $\mathrm{K}((1 / 4) \mathrm{K}) \mathbf{2 K}$ & $\mathrm{K}((1 / 4) \mathrm{K}) \mathbf{2 K}$ & $\mathrm{K}((1 / 4) \mathrm{K}) \mathbf{2 K}$ \\
\hline 24 & $164.1(129.0) \mathbf{1 6 4 . 1}$ & $23.5(23.1) \mathbf{1 8 . 8}$ & $10.7(17.8) \mathbf{6 . 2}$ \\
48 & $175.7(114.8) \mathbf{1 8 6 . 3}$ & $50.1(57.5) \mathbf{4 7 . 8}$ & $26.6(37.2) \mathbf{2 1 . 8}$ \\
72 & $88.4(159.8) \mathbf{1 6 1 . 5}$ & $35.9(55.5) \mathbf{3 4 . 9}$ & $20.0(33.6) \mathbf{1 6 . 0}$ \\
96 & $139.1(429.8) \mathbf{1 8 9 . 1}$ & $33.2(49.2) \mathbf{2 4 . 3}$ & $13.7(29.5) \mathbf{8 . 2}$ \\
6-hourly & $118.8(151.9) \mathbf{1 5 5 . 3}$ & $32.5(38.5) \mathbf{2 8 . 0}$ & $16.2(25.5) \mathbf{1 2 . 7}$ \\
MAE & & &
\end{tabular}

$(151.9 \mathrm{~km})$. As shown in Figure 6(d), the CSLP time series simulated by the 3 versions are close to each other. In terms of MWSP, the K200 and the original YSU can perform better than the K025 (Figure 6(e)).

3.1.6. Case 6: Nuri. For the super typhoon Nuri (2014), the CSLP time series simulated by the K200 and the original YSU are very close (Figure 7(d)). As shown in Table 7, the MAE of track, CSLP, and MWSP simulated by the K025 are the worst. The MAEs of track, CSLP, and MWSP simulated by the original YSU and the K200 are close to each other (Table 7).

3.1.7. Case 7: Hagupit. During the first 2 days of the simulations, the CSLP time series are close to each other (Figure $8(\mathrm{~d})$ ) and have large AEs comparing with observations. As shown in Table 8 , at $t=48 \mathrm{~h}$, the AE of CSLP simulated by the original YSU, the K025, and the K200 are 50.1, 57.5, and $47.8 \mathrm{hPa}$, respectively. In Figure 8(e), the MWSP simulated by the $\mathrm{K} 200$ is the strongest among all the 3 versions, which maybe resulted from larger heat and moisture fluxes. 

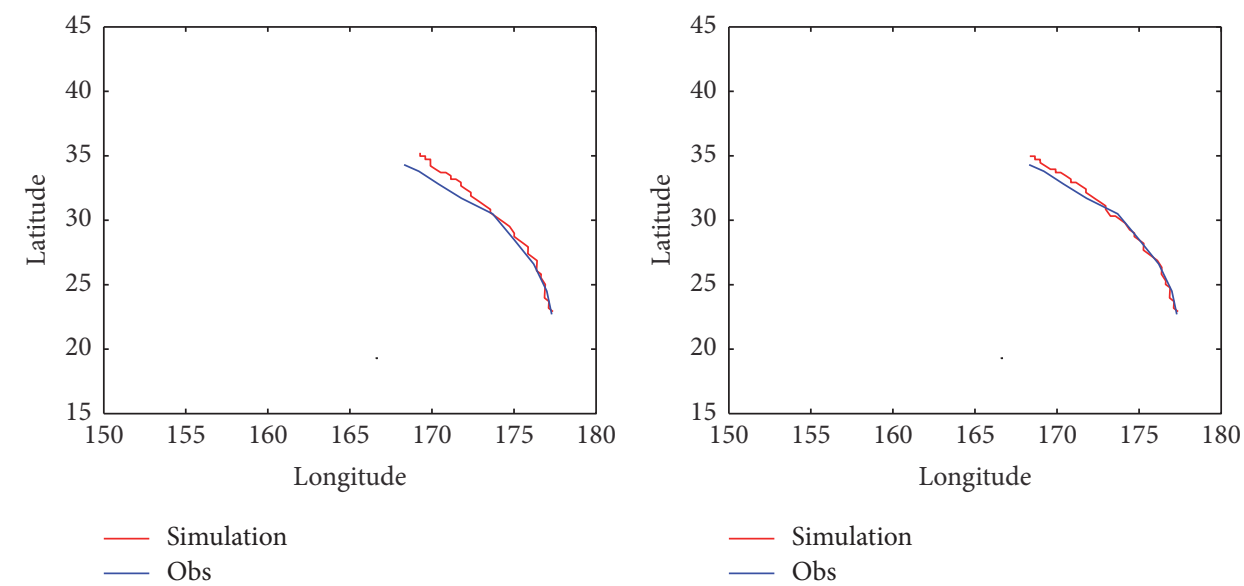

(a)

(b)
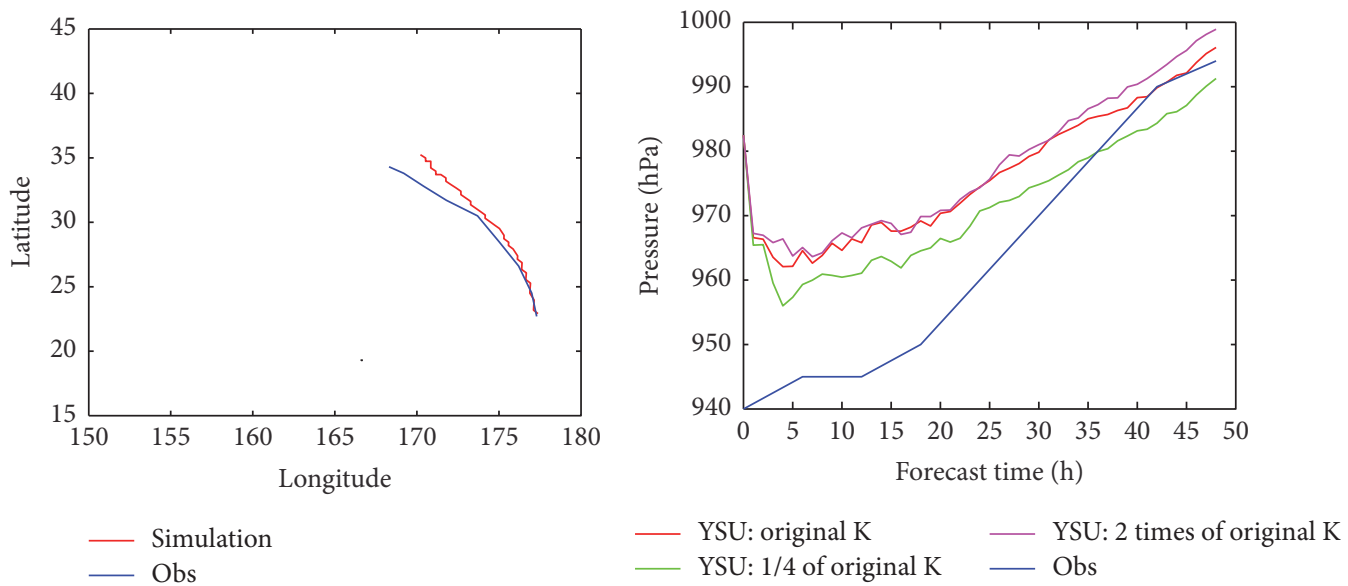

(c)

(d)

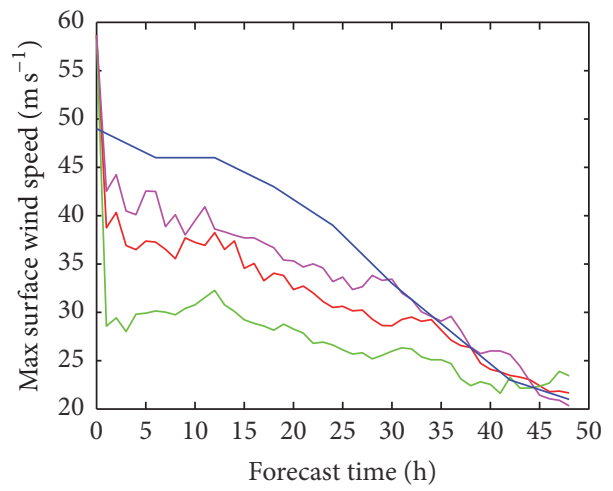

- YSU: original K Y YSU: 2 times of original K

(e)

FIgURE 4: Case 3-Genevieve: (a) track simulated by the original YSU; (b) track simulated by the K025; (c) track simulated by the K200; (d) comparisons of center sea-level pressure; and (e) comparisons of maximum surface wind speed.

3.1.8. Summary. In general, for all the 7 super typhoons, the simulations by the K200 always provide the best MWSP prediction, in the sense of lowest MAE. For track and CSLP, we use the averaged AEs and MAEs to evaluate the overall performance of these 3 versions. It is observed that the intensity simulated with larger eddy diffusivity is likely to be stronger.

3.2. Overall Performance. The averaged AEs at $t=24,48$, 72, $96 \mathrm{~h}$ are listed in Table 9. In Table 9, a number in bold 


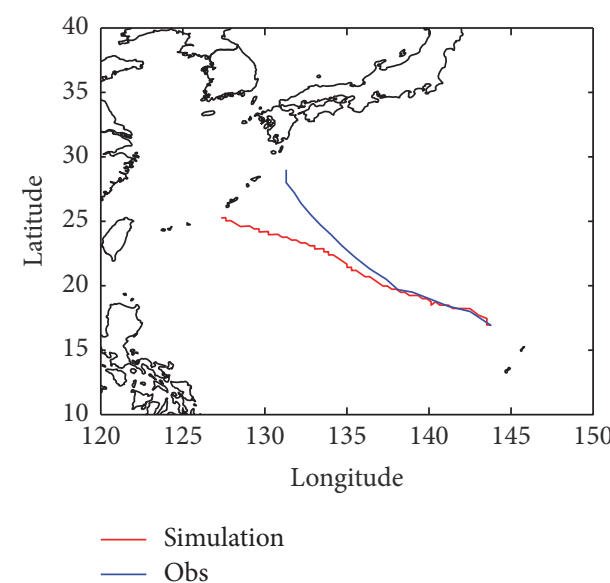

(a)

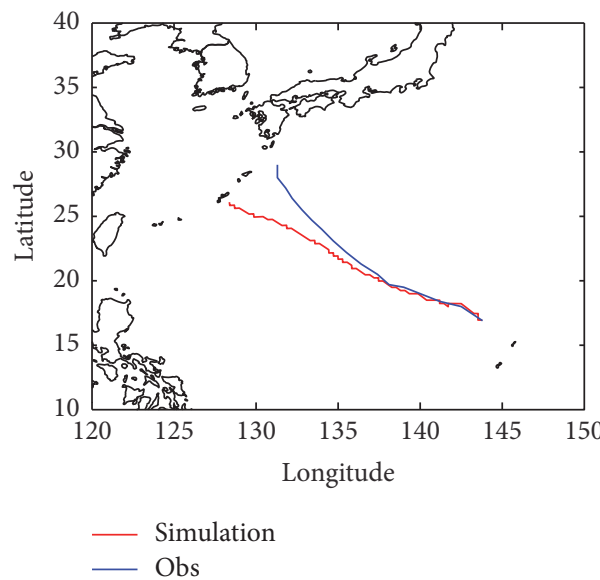

(c)

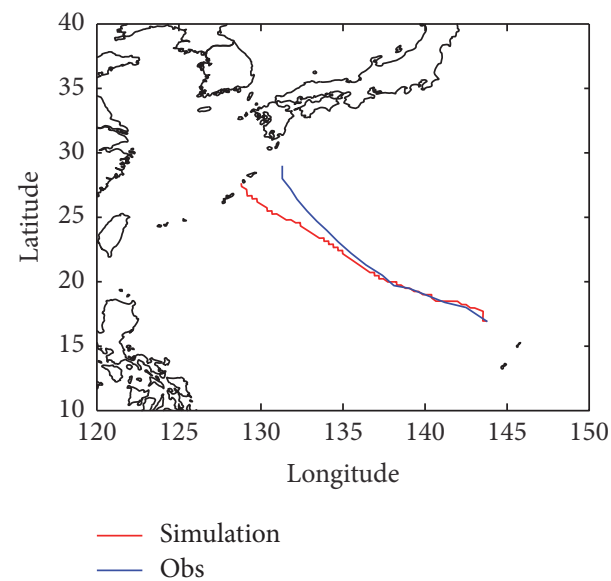

(b)

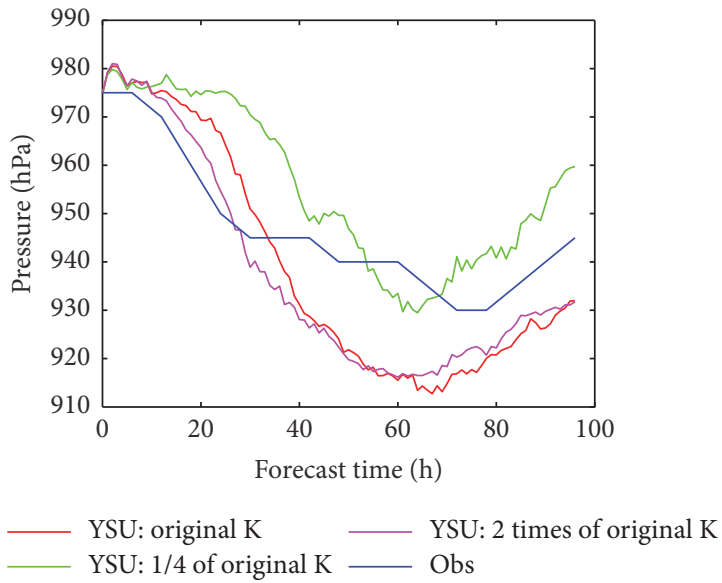

(d)

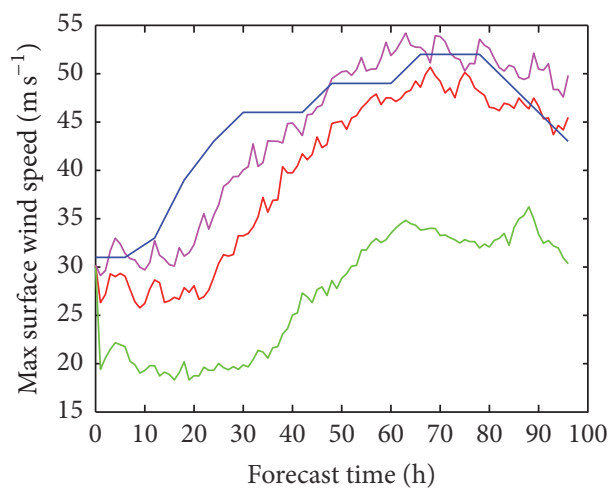

$\begin{array}{ll}\text { YSU: original } \mathrm{K} & \text { YSU: } 2 \text { times of original } \mathrm{K} \\ \text { YSU: } 1 / 4 \text { of original } \mathrm{K} & \text { Obs }\end{array}$

(e)

FIgURE 5: Case 4-Phanfone: (a) track simulated by the original YSU; (b) track simulated by the K025; (c) track simulated by the K200; (d) comparisons of center sea-level pressure; and (e) comparisons of maximum surface wind speed.

means that the corresponding K-profile can provide the best performance for that averaged AE or MAE. It shows that the K200 provides the best performance for all the AEs and MAEs, except for the averaged AE of $48 \mathrm{~h}$-CSLP. For all the averaged MAEs, the K200 can always provide the best performance. For the averaged AEs of $24 \mathrm{~h}$-track, $48 \mathrm{~h}$ track, $72 \mathrm{~h}$-track, and $96 \mathrm{~h}$-track, the $\mathrm{K} 200$ reduces/improves them by $3.6-8.5 \%$, whereas the K025 increases/deteriorates them by $9.6-39.1 \%$. The K200 improves the averaged AEs of $24 \mathrm{~h}$-CSLP and $96 \mathrm{~h}$-CSLP by $23.1 \%$ and $20.8 \%$, respectively. 


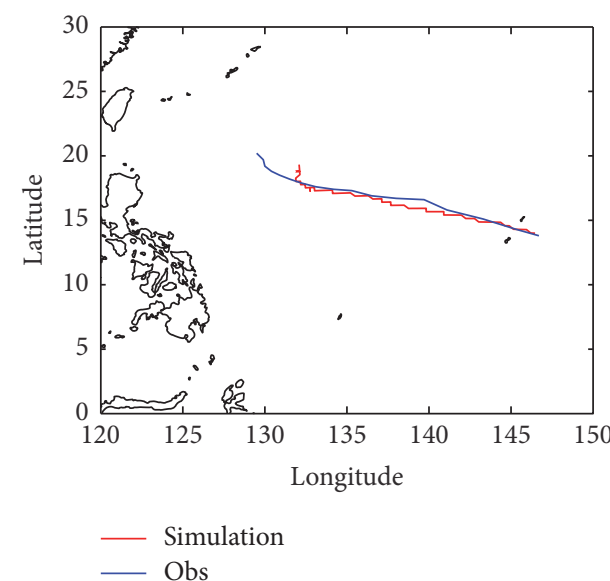

(a)

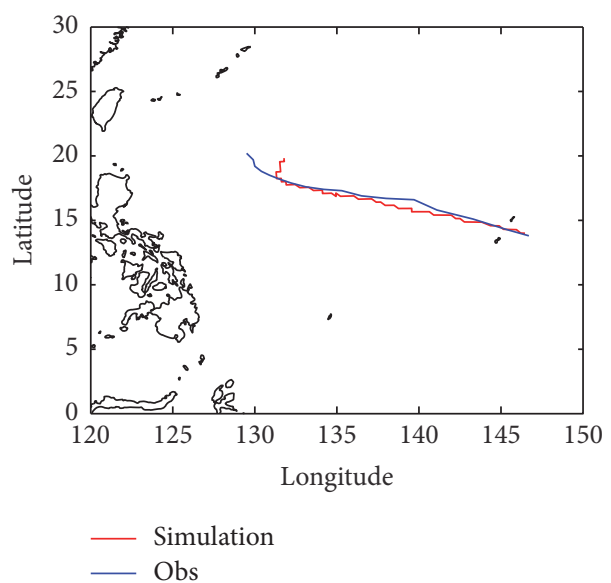

(c)

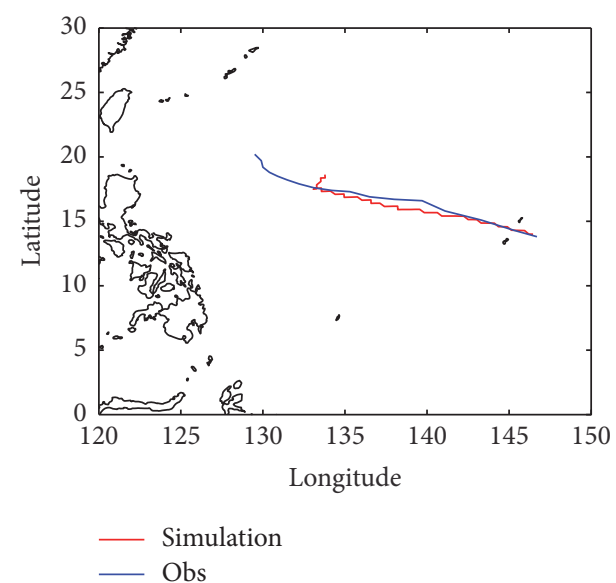

(b)

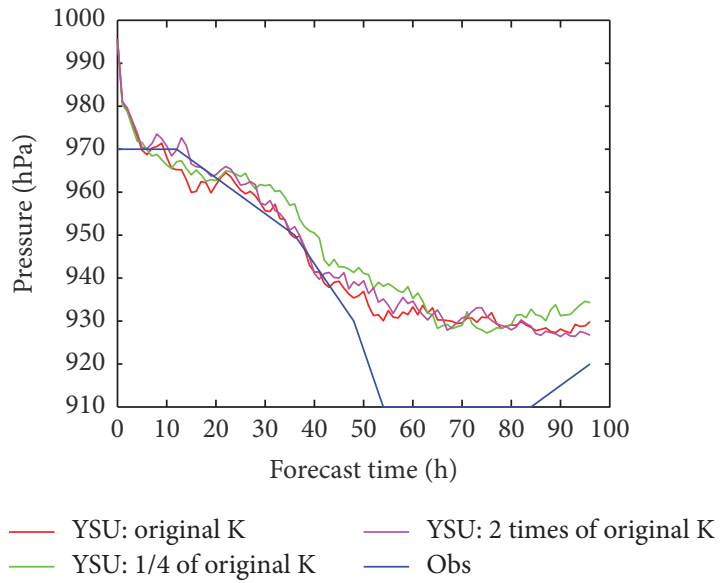

(d)

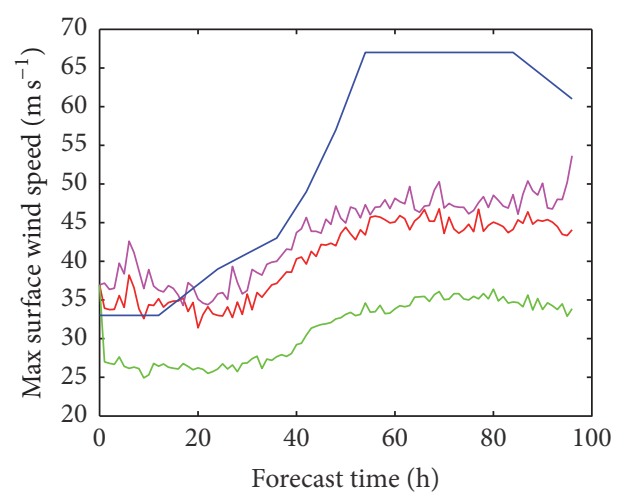

$\begin{array}{ll}\text { YSU: original } \mathrm{K} & \text { YSU: } 2 \text { times of original } \mathrm{K} \\ \text { YSU: } 1 / 4 \text { of original } \mathrm{K} & \text { Obs }\end{array}$

(e)

FIGURE 6: Case 5-Vongfong: (a) track simulated by the original YSU; (b) track simulated by the K025; (c) track simulated by the K200; (d) comparisons of center sea-level pressure; and (e) comparisons of maximum surface wind speed.

However, the K025 deteriorates the averaged AEs of $24 \mathrm{~h}$ CSLP and 96 h-CSLP by $40.3 \%$ and $54.0 \%$, respectively. For the averaged AEs of $24 \mathrm{~h}$-MWSP, $48 \mathrm{~h}$-MWSP, $72 \mathrm{~h}$-MWSP, and $96 \mathrm{~h}-\mathrm{MWSP}$, the K200 improves them by $16.1-50.1 \%$, whereas the K025 deteriorates them by $78.1-105.9 \%$.
Comparing with the original version, the K200 improves the averaged MAEs of track, CSLP, and MWSP by $6.0 \%, 3.7 \%$, and $23.1 \%$, respectively. However, the K025 deteriorates the averaged MAEs of track, CSLP, and MWSP by $25.1 \%, 19.0 \%$, and $95.0 \%$, respectively. 


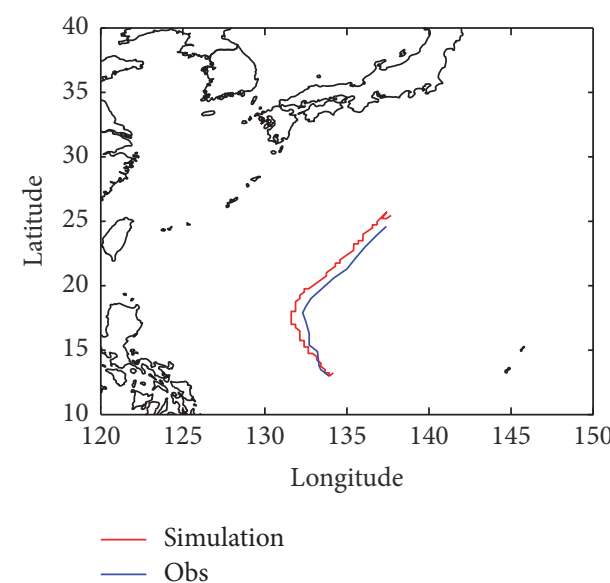

(a)

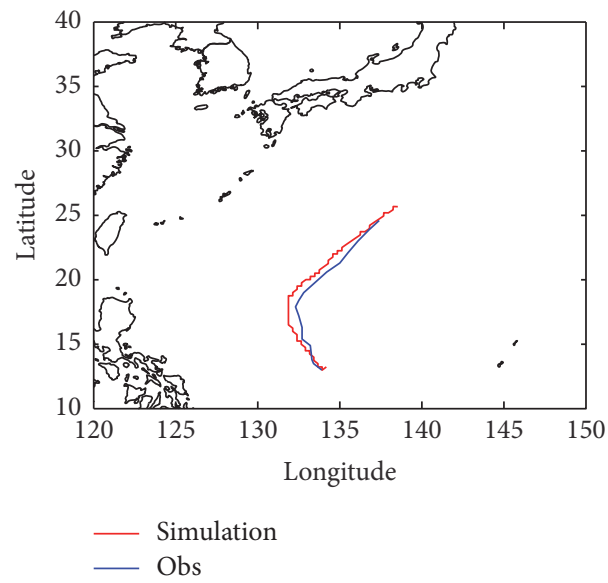

(c)

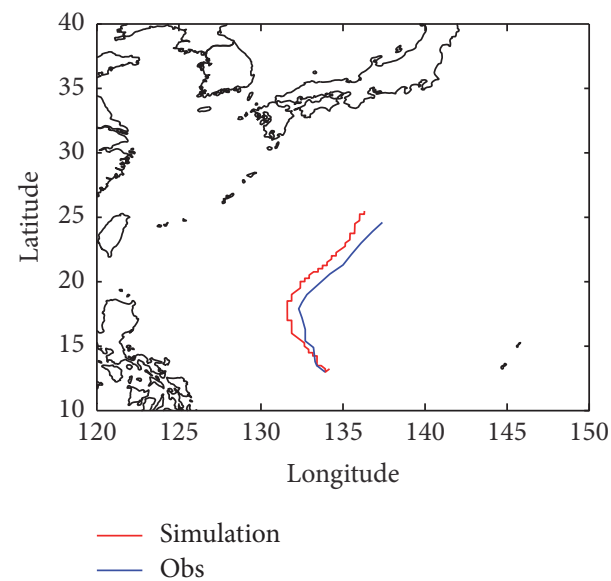

(b)

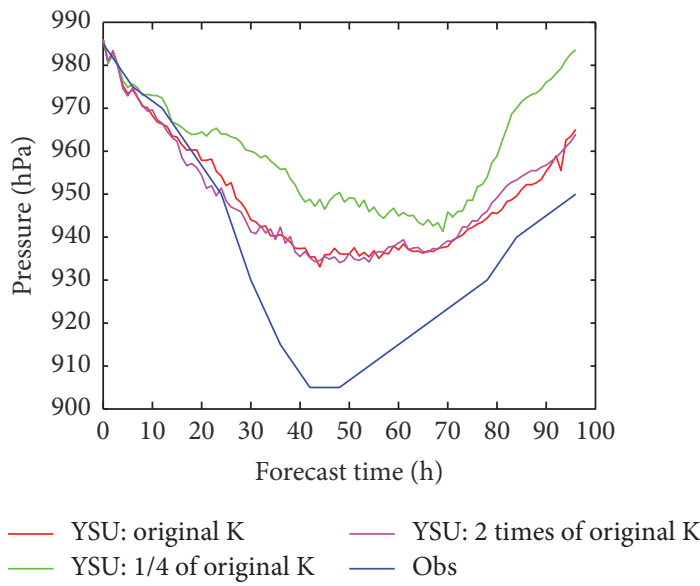

(d)

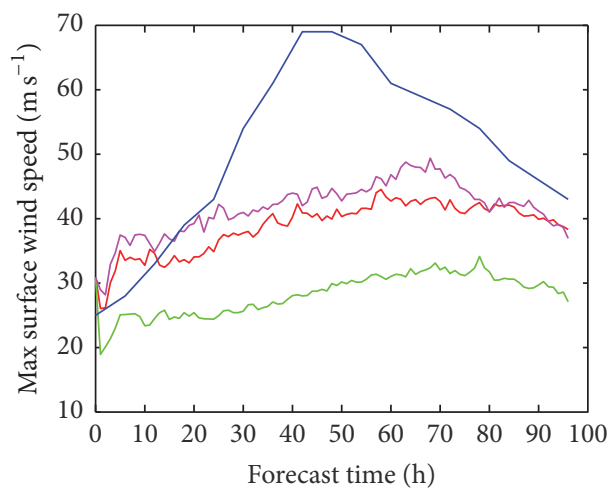

$\begin{array}{ll}\text { YSU: original } \mathrm{K} & - \text { YSU: } 2 \text { times of original } \mathrm{K} \\ \text { YSU: } 1 / 4 \text { of original K } & \text { Obs }\end{array}$

(e)

Figure 7: Case 6-Nuri: (a) track simulated by the original YSU; (b) track simulated by the K025; (c) track simulated by the K200; (d) comparisons of center sea-level pressure; and (e) comparisons of maximum surface wind speed.

To test the sensitivity of the enlarged eddy diffusion coefficients, the $K_{m}$ and $K_{h}$ are also modified to be 3 times their original values in a new version of K-profile, which is named as K300. We use the super typhoon Phanfone (2014) to give an example. In Figure 9, the track, CSLP, and MWSP of 4 different versions (original YSU, K025, K200, and K300) are compared. It can be observed in Figure 9(a) that the track simulated by the original YSU is the worst and the track simulated by the $\mathrm{K} 025$ is the best. The tracks simulated by the K200 and the K300 are close to each other. From Figure 9(b), 

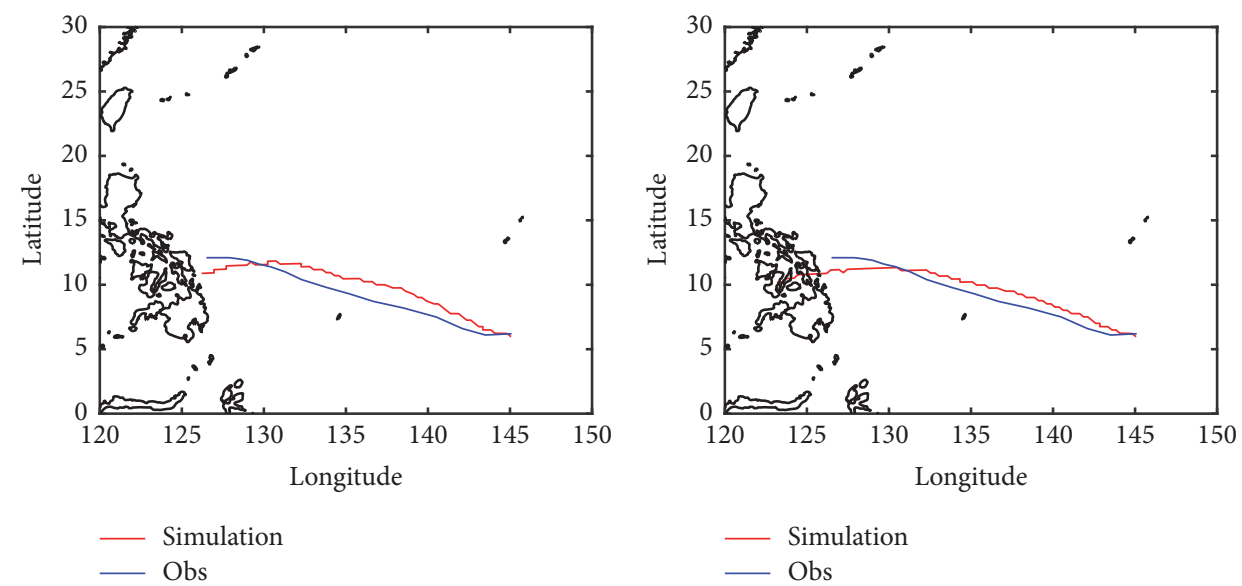

(a)

(b)
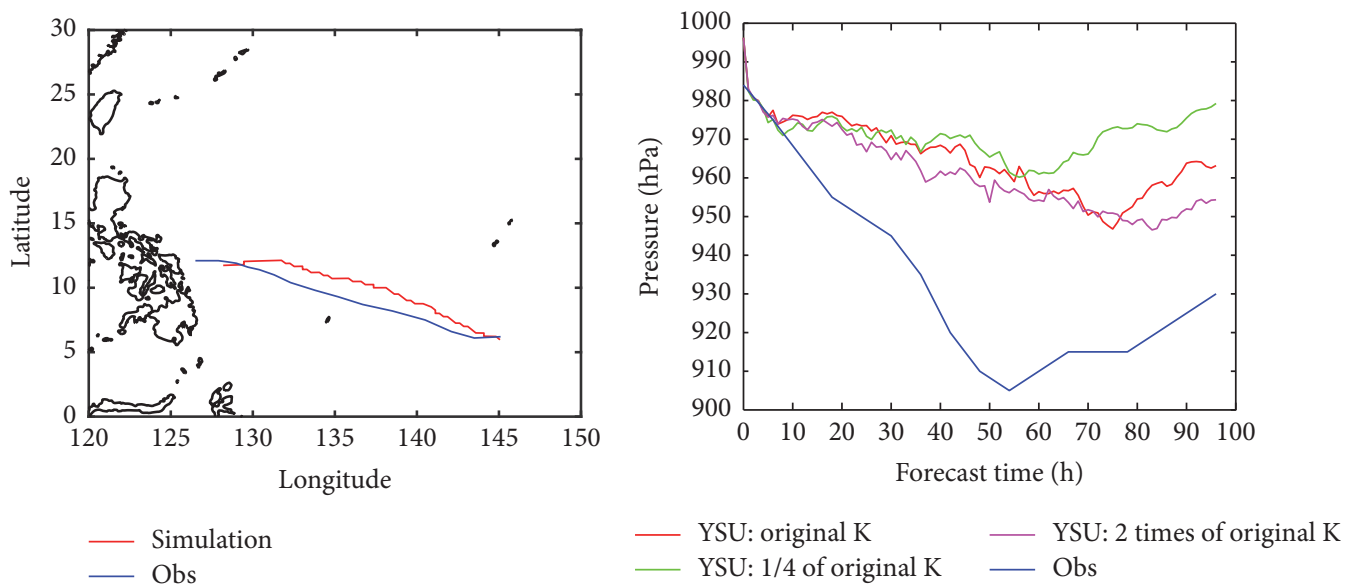

(c)

(d)

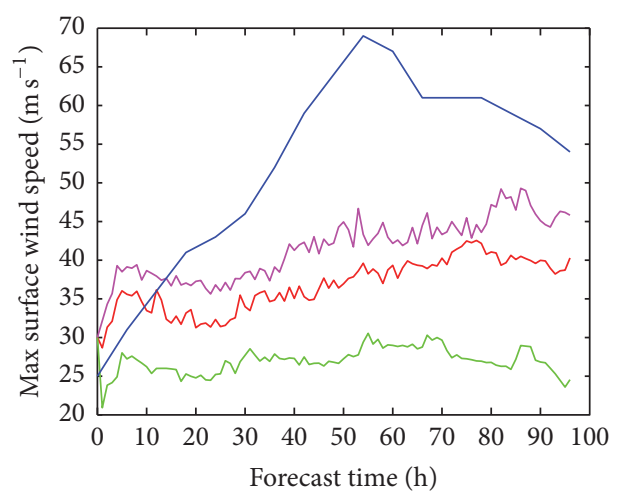

YSU: original $\mathrm{K}$
YSU: $1 / 4$ of original $\mathrm{K}-$ YSU: 2 times of original $\mathrm{K}$
Obs

(e)

FIGURE 8: Case 7-Hagupit: (a) track simulated by the original YSU; (b) track simulated by the K025; (c) track simulated by the K200; (d) comparisons of center sea-level pressure; and (e) comparisons of maximum surface wind speed.

it is observed that the CSLP time series simulated by the original YSU, the K200, and the K300 are close to each other, especially during the last 2 days of the simulation period. In Figure 9(c), the MWSP time series simulated by the K200 and the $\mathrm{K} 300$ are close to each other during the whole simulation period. These results indicate that the typhoon intensity may not be sensible to the magnitudes of enlarged eddy diffusion coefficients. 


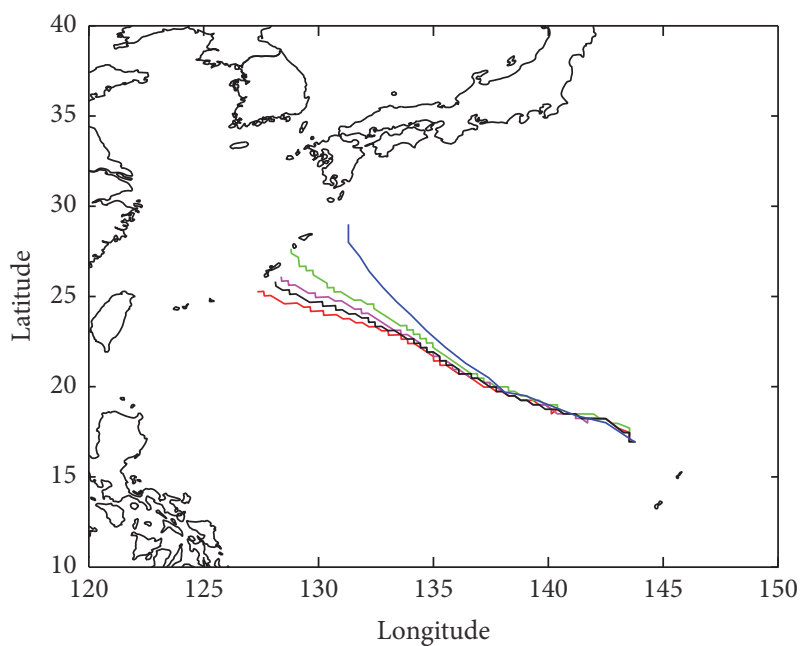

YSU: original $\mathrm{K}$
YSU: $1 / 4$ of original $\mathrm{K}$
YSU: 2 times of original K

(a)

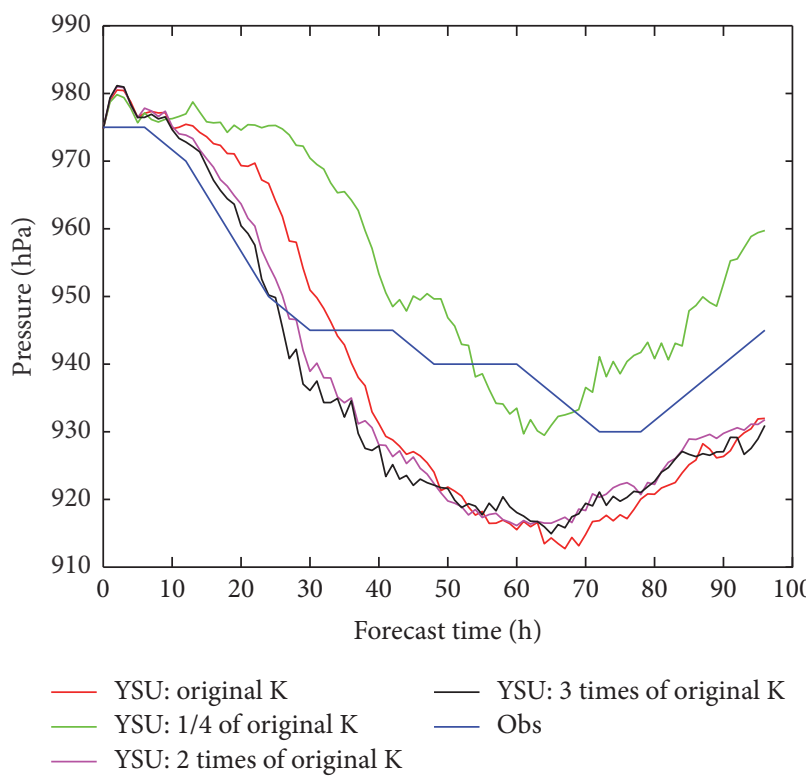

(b)

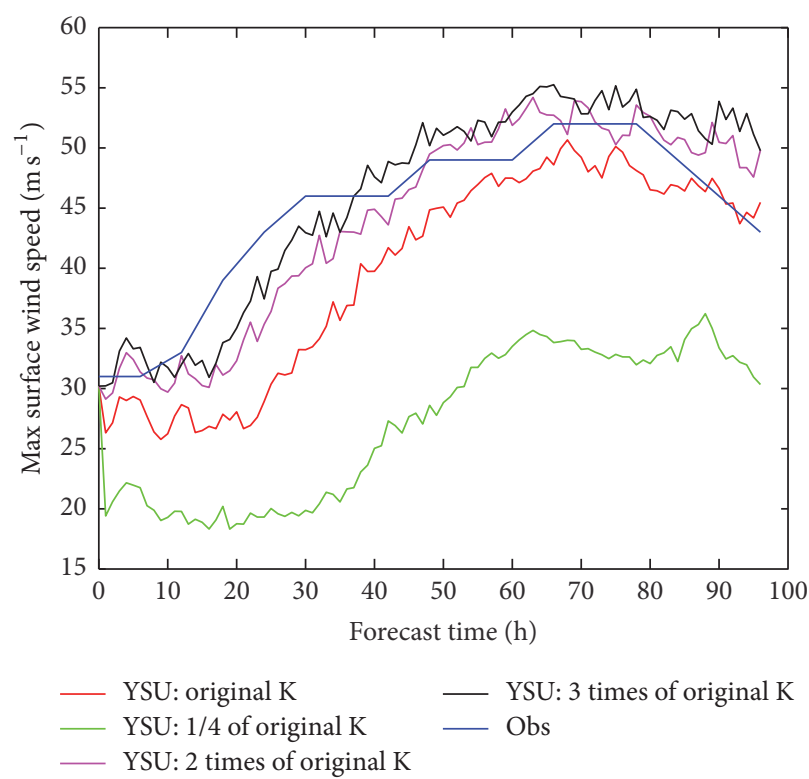

(c)

FIGURE 9: Track, CSLP, and MWSP of super typhoon Phanfone (2014) simulated by the original YSU, the K025, the K200, and the K300.

\section{Conclusions}

In this article, WRF simulations for super typhoons are used to evaluate 3 versions of the YSU scheme. For all the averaged MAEs, the K200 can always provide the best performance. For all the super typhoon cases, the simulations with the K200 can always provide the best MWSP prediction.

Comparing with the original version, the K200 improves the averaged MAEs of track, CSLP, and MWSP by $6.0 \%$, $3.7 \%$, and $23.1 \%$, respectively, whereas the K025 deteriorates the averaged MAEs of track, CSLP, and MWSP by $25.1 \%$,
$19.0 \%$, and $95.0 \%$, respectively. Our results suggest that the enlarged eddy diffusion coefficients may be more suitable for super typhoon simulations, because that larger eddy diffusion coefficients for heat and moisture can induce larger sensible and latent heat fluxes.

However, we shall also notice that this study is limited to the YSU PBL scheme and the WRF-ARW model. The modifications to the eddy diffusion coefficients also cannot be applied to the higher-order closure models, for example, Wyngaard and Coté [10], and Enger [11]. Besides, the study is also limited to the simple choices of the parameter $\alpha$. In the 
TABLE 9: Averaged AEs and MAEs of track, CSLP, and MWSP simulated by the original YSU, the K025, and the K200.

\begin{tabular}{|c|c|c|c|c|c|}
\hline AveragedAE/MAE & Original YSU & K025 & K200 & Improvementby K025 & Improvementby K200 \\
\hline $24 \mathrm{~h}$-track & 92.8 & 102.5 & 87.2 & $-10.4 \%$ & $6.1 \%$ \\
\hline $48 \mathrm{~h}$-track & 122.7 & 134.4 & 115.3 & $-9.6 \%$ & $6.0 \%$ \\
\hline 72 h-track & 153.1 & 207.1 & 147.6 & $-35.2 \%$ & $3.6 \%$ \\
\hline 96 h-track & 245.4 & 341.3 & 224.5 & $-39.1 \%$ & $8.5 \%$ \\
\hline MAE of track & 119.8 & 149.8 & 112.6 & $-25.1 \%$ & $6.0 \%$ \\
\hline 24 h-CSLP & 11.8 & 16.6 & 9.1 & $-40.3 \%$ & $23.1 \%$ \\
\hline 48 h-CSLP & 22.1 & 21.8 & 23.2 & $1.3 \%$ & $-5.0 \%$ \\
\hline $72 \mathrm{~h}-\mathrm{CSLP}$ & 18.2 & 21.4 & 17.7 & $-17.3 \%$ & $2.7 \%$ \\
\hline 96 h-CSLP & 17.3 & 26.6 & 13.7 & $-54.0 \%$ & $20.8 \%$ \\
\hline MAE of CSLP & 16.0 & 19.1 & 15.4 & $-19.0 \%$ & $3.7 \%$ \\
\hline 24 h-MWSP & 8.7 & 17.2 & 4.4 & $-96.9 \%$ & $50.1 \%$ \\
\hline 48 h-MWSP & 13.0 & 23.1 & 10.9 & $-78.1 \%$ & $16.1 \%$ \\
\hline $72 \mathrm{~h}-\mathrm{MWSP}$ & 11.7 & 23.6 & 8.3 & $-101.5 \%$ & $29.2 \%$ \\
\hline 96 h-MWSP & 10.7 & 22.0 & 7.3 & $-105.9 \%$ & $32.0 \%$ \\
\hline MAE of MWSP & 9.8 & 19.2 & 7.6 & $-95.0 \%$ & $23.1 \%$ \\
\hline
\end{tabular}

future study, it is necessary to find out why the performance of the K-profiles is case-dependent.

\section{Competing Interests}

The authors declare that there is no conflict of interests regarding the publication of this paper.

\section{Acknowledgments}

The authors appreciate the assistance of the HKO, which provided the meteorological data. This work was supported by NSFC/RGC Grant N_HKUST631/05, NSFC-FD Grant U1033001, and the RGC Grant 16300715.

\section{References}

[1] J. O'brien, "A note on the vertical structure of the eddy exchange coefficient in the planetary boundary layer," Journal of the Atmospheric Sciences, vol. 27, no. 8, pp. 1213-1215, 1970.

[2] R. A. Brost and J. C. Wyngaard, "A model study of the stably stratified planetary boundary layer," Journal of the Atmospheric Sciences, vol. 35, no. 8, pp. 1427-1440, 1978.

[3] I. B. Troen and L. Mahrt, "A simple model of the atmospheric boundary layer: sensitivity to surface evaporation," BoundaryLayer Meteorology, vol. 37, no. 1-2, pp. 129-148, 1986.

[4] S.-Y. Hong and H.-L. Pan, "Nonlocal boundary layer vertical diffusion in a medium-range forecast model," Monthly Weather Review, vol. 124, no. 10, pp. 2322-2339, 1996.

[5] J. W. Deardorff, "Theoretical expression for the countergradient vertical heat flux," Journal of Geophysical Research, vol. 77, no. 30, pp. 5900-5904, 1972.

[6] S.-Y. Hong, Y. Noh, and J. Dudhia, "A new vertical diffusion package with an explicit treatment of entrainment processes," Monthly Weather Review, vol. 134, no. 9, pp. 2318-2341, 2006.

[7] Y. Noh, W. G. Cheon, S. Y. Hong, and S. Raasch, "Improvement of the K-profile model for the planetary boundary layer based on large eddy simulation data," Boundary-Layer Meteorology, vol. 107, no. 2, pp. 401-427, 2003.
[8] S. G. Gopalakrishnan, F. Marks Jr., J. A. Zhang, X. Zhang, J.W. Bao, and V. Tallapragada, "A study of the impacts of vertical diffusion on the structure and intensity of the tropical cyclones using the high-resolution HWRF system," Journal of the Atmospheric Sciences, vol. 70, no. 2, pp. 524-541, 2013.

[9] J. A. Zhang and W. M. Drennan, "An observational study of vertical eddy diffusivity in the hurricane boundary layer," Journal of the Atmospheric Sciences, vol. 69, no. 11, pp. 32233236, 2012.

[10] J. C. Wyngaard and O. R. Coté, “The evolution of a convective planetary boundary layer-A Higher-Order-Closure Model Study," Boundary-Layer Meteorology, vol. 7, no. 3, pp. 289-308, 1974.

[11] L. Enger, "A higher order closure model applied to dispersion in a convective PBL," Atmospheric Environment, vol. 20, no. 5, pp. 879-894, 1986. 

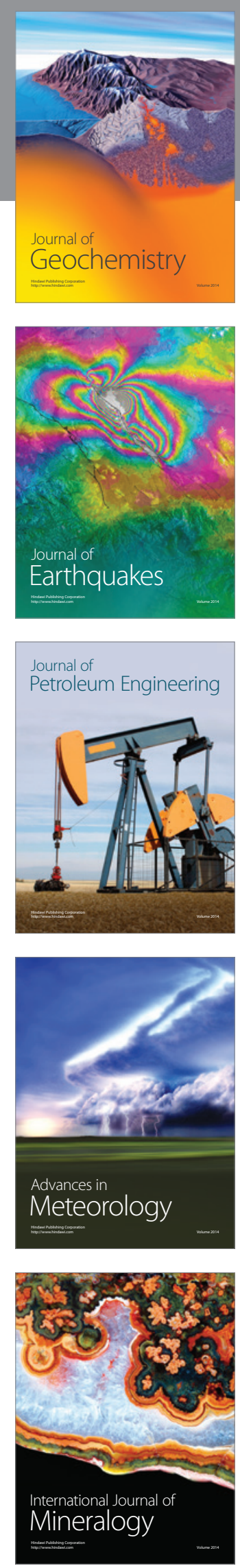
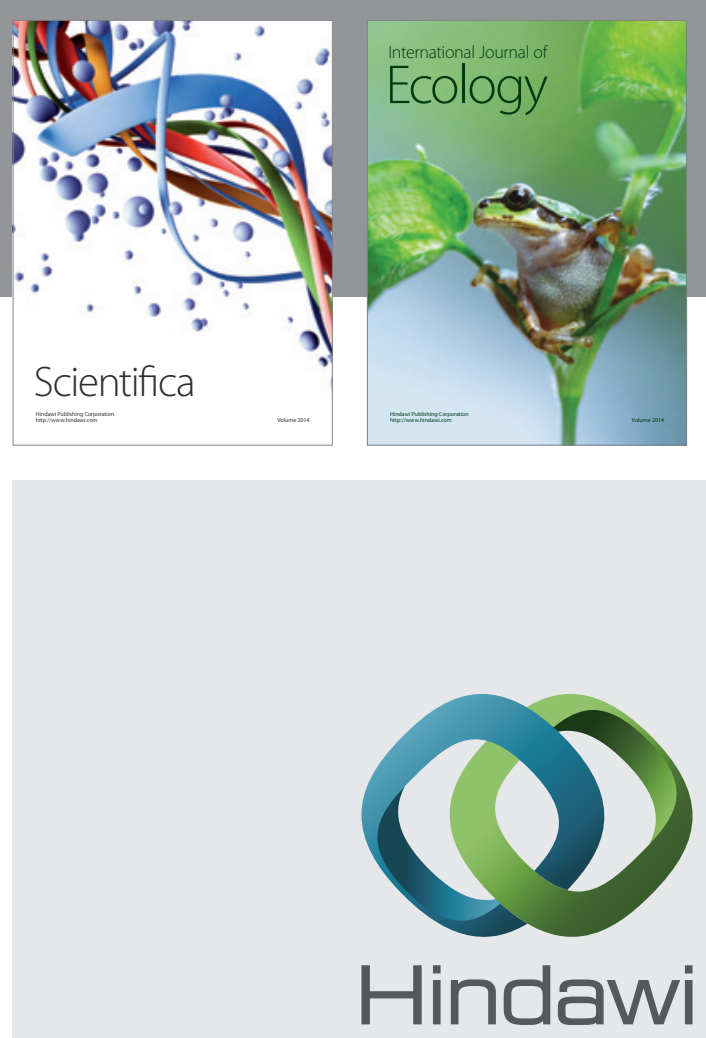

Submit your manuscripts at

http://www.hindawi.com
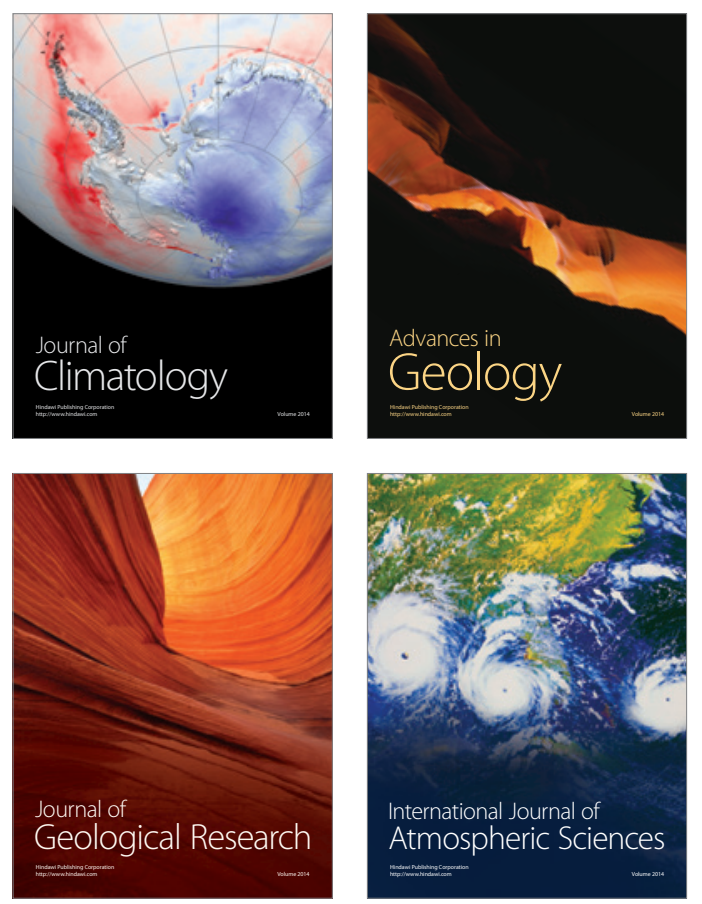

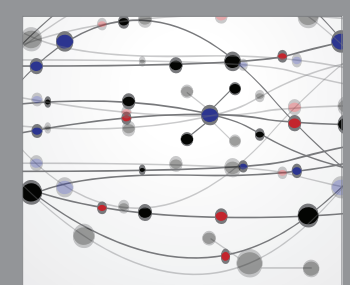

The Scientific

\section{World Journal}
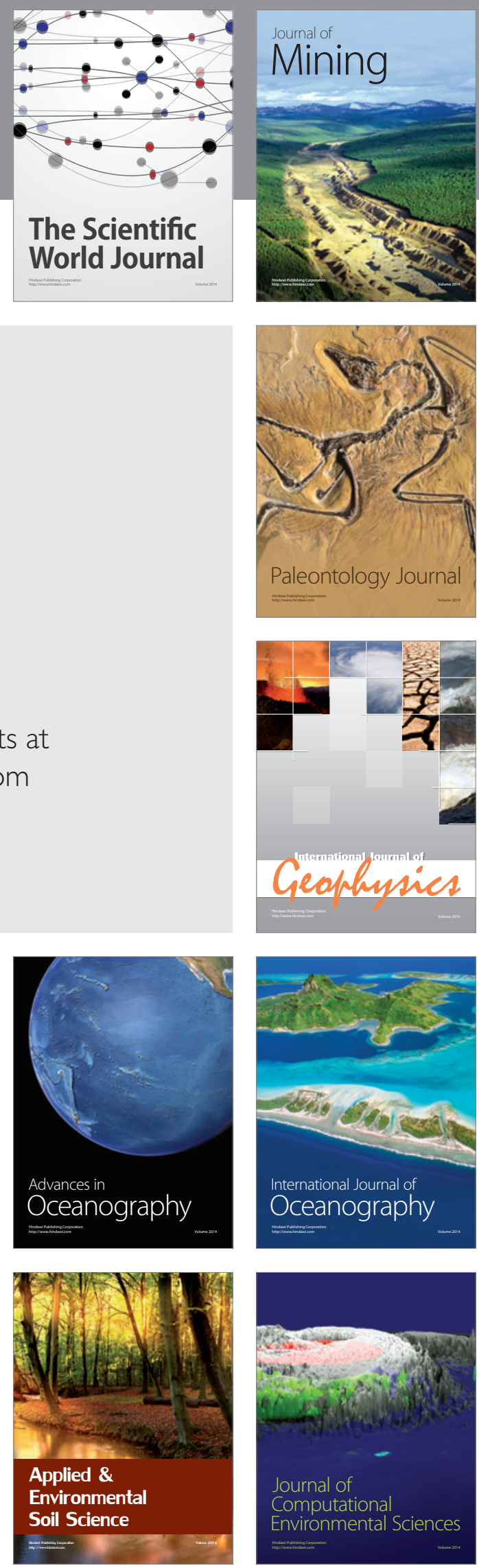